\title{
No-shows to primary care appointments: subsequent acute care utilization among diabetic patients
}

Lynn A Nuti ${ }^{1}$, Mark Lawley ${ }^{2}$, Ayten Turkcan ${ }^{3}$, Zhiyi Tian ${ }^{4}$, Lingsong Zhang ${ }^{4,5}$, Karen Chang ${ }^{1}$, Deanna R Willis ${ }^{6}$ and Laura P Sands ${ }^{7^{*}}$

\begin{abstract}
Background: Patients who no-show to primary care appointments interrupt clinicians' efforts to provide continuity of care. Prior literature reveals no-shows among diabetic patients are common. The purpose of this study is to assess whether no-shows to primary care appointments are associated with increased risk of future emergency department (ED) visits or hospital admissions among diabetics.

Methods: A prospective cohort study was conducted using data from 8,787 adult diabetic patients attending outpatient clinics associated with a medical center in Indiana. The outcomes examined were hospital admissions or ED visits in the 6 months (182 days) following the patient's last scheduled primary care appointment. The Andersen-Gill extension of the Cox proportional hazard model was used to assess risk separately for hospital admissions and ED visits. Adjustment was made for variables associated with no-show status and acute care utilization such as gender, age, race, insurance and co-morbid status. The interaction between utilization of the acute care service in the six months prior to the appointment and no-show was computed for each model.

Results: The six-month rate of hospital admissions following the last scheduled primary care appointment was 0.22 $($ s.d. $=0.83)$ for no-shows and $0.14($ s.d. $=0.63)$ for those who attended $(p<0.0001)$. No-show was associated with greater risk for hospitalization only among diabetics with a hospital admission in the prior six months. Among diabetic patients with a prior hospital admission, those who no-showed were at $60 \%$ greater risk for subsequent hospital admission ( $H R=1.60, \mathrm{Cl}=1.17-2.18)$ than those who attended their appointment. The six-month rate of ED visits following the last scheduled primary care appointment was 0.56 (s.d. $=1.48)$ for no-shows and 0.38 (s.d. $=1.05$ ) for those who attended ( $p<0.0001$ ); after adjustment for covariates, no-show status was not significantly related to subsequent ED utilization.
\end{abstract}

Conclusions: No-show to a primary care appointment is associated with increased risk for hospital admission among diabetics recently hospitalized.

Keywords: No-show, Diabetes, Emergency department visits, Hospital admissions, Outcomes

\footnotetext{
* Correspondence: Isands@purdue.edu

${ }^{7}$ School of Nursing, College of Health and Human Sciences, Center for Aging

and the Life Course, Purdue University, 502 N. University Street, West

Lafayette, IN 47907-2069, USA

Full list of author information is available at the end of the article
} 


\section{Background}

Diabetes is a rising health care concern as its prevalence continues to grow in the United States. Diabetes mellitus was ranked as the seventh leading cause of death in 2009 [1]. In 2007, $\$ 218$ billion was spent in total estimated costs for diabetes, with $\$ 153$ billion due to medical costs and $\$ 65$ billion due to reduced productivity [2]. There were nearly 125 million visits to Emergency Departments (ED) in 2008 and over 98.5 million were for adults; the most frequent reasons for adult ED visits revealed that diabetes mellitus without complications ranked third (9.3\%) of all ED visits [3]. In 2007, an estimated $\$ 3.87$ billion was attributed to emergency department costs for diabetes [4]. In 2008 over 7.7 million hospital admissions and $\$ 83$ billion in costs were attributed to diabetes [5].

Complications and costs from diabetes can be reduced by consistent and effective disease management [6]. For effective diabetes management, national clinical practice guidelines recommend patients visit their healthcare provider every 3 to 6 months [6]. For a majority of patients, the primary care provider (PCP) manages their diabetic care and patients whose diabetes is managed by a specialist rely upon their PCP for supervising their complete care [7]. Promotion of diabetes management is, in part, dependent upon patient adherence with medical appointments with their PCP. When a patient misses an appointment without canceling a no-show occurs. No-shows to primary care appointments can interrupt continuity of care and effective disease management. Studies report that no-show rates for patients with diabetes range from $4 \%$ to $40 \%$ [8-13]. In addition, literature indicates that diabetic patients with higher noshow rates have higher glycosylated hemoglobin (A1C) levels and therefore, poorer glycemic control than those patients that attended appointments [8,11,13-16].

Diabetes is one of several chronic conditions that are considered ambulatory care sensitive conditions. Ambulatory care sensitive conditions are those that if treated in a timely and effective manner in the ambulatory care setting should not require acute care services [17]. Use of acute care services for ambulatory care sensitive conditions is considered evidence of a breakdown in outpatient care [18]. A study of hospital claims data from a nationally representative sample of Medicare recipients with diabetes revealed that seven percent of hospitalizations were for diagnoses that have been characterized as ambulatory care sensitive conditions [18]. Similarly, four percent of ED visits are for diagnoses associated with ambulatory care sensitive conditions [19]. To our knowledge, no prior studies have assessed whether no-shows to primary care appointments are associated with increased risk of subsequent ED visits or hospital admissions.
The hypothesis underlying this study is that diabetic patients who no-show to primary care appointments have higher risk for subsequent ED visits and hospital admissions than those who do not miss their scheduled primary care visits. A secondary hypothesis is that compared to patients who attended their last appointment, patients who no-show would be more likely to have admission diagnoses for their subsequent acute care admissions that are sensitive to diabetes-associated ambulatory care.

\section{Methods}

\section{Study Design}

A prospective cohort study was conducted to examine ED visits and hospital admissions six months following the last scheduled primary care appointment. This study was approved by the Institutional Review Boards of Indiana University School of Medicine and Purdue University.

\section{Patient participants}

Patients attending outpatient clinics associated with an academic medical center in Indiana were included in the sample. The sample consisted of 9,411 patients with two or more billing records with International Classification of Diseases (ICD-9) diabetes codes (250.xx, 357.2, 362.0, and 366.41). Only adults, 18 years of age or older, with the above ICD-9 codes were included in the sample $(\mathrm{N}=9,393)$. Diabetic patients with one or more scheduled appointments within the last 2 years $(\mathrm{N}=9,387)$ were included if they had clinical information in the medical records database one year prior to and one year after the last scheduled primary care appointment $(\mathrm{N}=8,787)$.

\section{Data sources}

Patient demographics, diagnoses, appointment history and characteristics, insurance and billing data were retrieved from scheduling and billing data collected during primary care visits occurring between January 2005 and June 2007. Hospital admission dates, emergency department visit dates, and primary diagnoses from January 2005 through to December 2007 were retrieved from the Regenstrief Medical Records System (RMRS) which covers over 1.5 million patients in the greater Indianapolis area. RMRS is utilized by three hospital systems associated with the medical clinics incorporated in this study, including the largest hospital system in Indianapolis.

\section{Independent variables}

In this study no-show status was defined as patients who did not show for their last scheduled primary care appointment. Patients who attended their last primary care appointment comprised the referent group. 


\section{Covariates}

Gender was included with female as the referent group. Age was categorized into four ranges: 18-30 years, $31-45$ years, $46-70$ years, and $\geq 70$ years with $18-30$ years of age designated as the referent group. Race was classified as black, white, other, and unknown with white as the referent group. Patient insurance coverage was categorized as Medicaid, Medicare, self-pay, county tax-funded program, and commercial insurance with commercial as the referent group. Cardiovascular complications from diabetes included atherosclerosis, angina pectoris, myocardial infarction, heart failure, aortic aneurysm/dissection, other ischemic heart disease (IHD) and other chronic IHD (ICD-9 codes, respectively: 440.xx, 413, 410, 428, 441, 411, and 414) [20]. Nephropathy complications from diabetes included diabetic nephropathy, acute glomerulonephritis, nephritic syndrome, hypertension nephrosis, chronic glomerulonephritis, nephritis/nephropathy, chronic renal failure, renal failure not otherwise specified (NOS), and renal insufficiency (ICD-9 codes, respectively: 250.4, 580, 581, 581.81,582, 583, 585, 586, 593.9) [20]. A Charlson co-morbidity score was computed to describe the number and severity of co-morbidities [21]. To compute this score a weight was applied to each co-morbidity, weights are founded on one-year mortality, and the weighted co-morbidities are totaled for each patient. Charlson co-morbidity scores can range from 0 to 27 with most patients falling below 3 . ED visits and hospital admissions in the six months prior to the last scheduled primary care appointment were included, with the referent groups being no ED or hospital admissions in the six months prior, respectively.

\section{Dependent variables}

In one model the dependent variable was time to ED visits within six months (182 days) following the patient's last scheduled primary care appointment. In the other model the dependent variable was time to hospital admissions within six months after the patient's last scheduled primary care appointment.

In an analysis addressing the secondary hypothesis, the dependent variables was whether or not the primary diagnosis the first hospital admission was for diabetes diagnoses described in prior publications as potentially preventable. For example, diagnoses included diabetes without mention of complication and diabetes with mention of ketoacidosis, hyperglycemia, hypoglcemia, coma, or an unspecified complication (ICD-9 $=250.0-250.3$, $250.8-250.10,250.12,250.13,250.20,250.22,250.23$, 250.30, 250.32, 250.33, 250.90, 250.92, or 250.93) [19].

\section{Statistical analyses}

Data analyses were conducted using SAS 9.2. Poisson regression models were computed to determine the bivariate association between each independent variable and each dependent variable. Independent variables with a $\mathrm{p}$-value of 0.20 or less were included in the multivariable models. The Andersen-Gill formulation of the Cox proportional hazard model was used to model the association between no-show at the last scheduled primary care appointment and ED or hospital utilization after adjustment for covariates related to ED or hospital utilization [22]. Unlike the traditional Cox proportional hazard models, the Andersen-Gill model accommodates the dependence between multiple event times that occur when a subject has more than one event (e.g. more than one hospital admission within six months) [22]. There are three different scenarios for calculating time to event (ED visits or hospital admissions). In the first scenario, there is no event and the time interval is defined as six months following the last scheduled primary care appointment. In the second scenario, there is one event within the 182 days following the last scheduled appointment. In this scenario the time interval is defined as days following the last scheduled primary care appointment up to and including the visit/admission date. In the third scenario, there are multiple events and the first time interval is defined as in scenario two above with subsequent time intervals beginning with the previous discharge date and extending to the date of the next visit/admission or the end of the observed interval. Intervals are discontinuous for hospital events because when subjects are hospitalized, they are not at risk of another admission until they have been discharged. A sandwich variance estimator was used to adjust the standard error estimates to account for the dependence among the repeated events within one subject (e.g. multiple ED visits). Each model included the interaction between utilization of the acute care service in the prior six months and no-show status.

In analyses to address whether the acute care admission was for an ambulatory care sensitive condition, a chi-square test was computed to examine the association between no-show status at the last scheduled appointment and whether or not the primary diagnosis was among the set considered to be a potentially preventable diabetes related diagnosis.

\section{Results}

Among the 8,787 patients included in this study, 1421 (16.2\%) did not show up to their last scheduled medical appointment. Table 1 reveals that the six-month rate of ED visits following the last scheduled primary care appointment was 0.56 (s.d. $=1.48$ ) for no-shows and 0.38 (s.d. $=1.05)$ those who attended $(p<0.0001)$. The sixmonth rate of hospital admissions following the last scheduled primary care appointment was 0.22 (s.d. = 0.83) for no-shows and 0.14 (s.d. $=0.63$ ) for those who attended 
Table 1 Bivariate analysis on ED visits or hospital admissions within 6 months after last scheduled primary care appointment

\begin{tabular}{|c|c|c|c|c|c|c|}
\hline $\mathrm{N}=8787$ & & $\mathrm{~N}(\%)$ & $\begin{array}{l}\text { ED visits in } \\
6 \text { months } \\
\text { mean (SD) }\end{array}$ & $P$ value* & $\begin{array}{l}\text { Hospital admissions } \\
\text { in } 6 \text { months } \\
\text { mean (SD) }\end{array}$ & $P$ value* \\
\hline \multirow[t]{2}{*}{ Gender } & Female & $5268(59.9 \%)$ & $0.43(1.16)$ & $<0.0001$ & $0.16(0.75)$ & 0.03 \\
\hline & Male & $3519(40.1 \%)$ & $0.36(1.09)$ & - & $0.14(0.52)$ & - \\
\hline \multirow[t]{4}{*}{ Age } & $18-30$ & $314(3.6 \%)$ & $0.68(1.42)$ & $<0.0001$ & $0.13(0.49)$ & 0.005 \\
\hline & $31-45$ & 1676(19.1\%) & $0.56(1.56)$ & $<0.0001$ & $0.12(0.48)$ & $<0.0001$ \\
\hline & $46-70$ & $5695(64.8 \%)$ & $0.36(1.01)$ & 0.28 & $0.15(0.73)$ & $<0.0001$ \\
\hline & $\geq 70$ & $1102(12.5 \%)$ & $0.33(0.80)$ & - & $0.21(0.62)$ & - \\
\hline \multirow[t]{4}{*}{ Race } & Black & $3655(41.6 \%)$ & $0.50(1.22)$ & $<0.0001$ & $0.17(0.65)$ & 0.01 \\
\hline & Other & $782(8.9 \%)$ & $0.28(0.98)$ & 0.001 & $0.13(1.21)$ & 0.11 \\
\hline & Unknown & $383(4.4 \%)$ & $0.18(0.56)$ & $<0.0001$ & $0.08(0.45)$ & 0.0004 \\
\hline & White & $3967(45.2 \%)$ & $0.36(1.11)$ & - & $0.15(0.54)$ & - \\
\hline \multirow[t]{4}{*}{ Insurance } & Medicaid & 779(8.9\%) & $0.74(1.88)$ & $<0.0001$ & $0.27(1.00)$ & $<0.0001$ \\
\hline & Medicare & $2746(31.3 \%)$ & $0.41(1.03)$ & $<0.0001$ & $0.21(0.63)$ & $<0.0001$ \\
\hline & Self-pay & $471(5.4 \%)$ & $0.47(1.49)$ & $<0.0001$ & $0.11(0.39)$ & 0.04 \\
\hline & County & 2792(31.8\%) & $0.46(1.16)$ & $<0.0001$ & $0.13(0.78)$ & $<0.0001$ \\
\hline \multicolumn{7}{|l|}{ Tax-funded } \\
\hline \multicolumn{7}{|l|}{ Program } \\
\hline & Commercial Insurance & 1999(22.8\%) & $0.17(0.56)$ & - & $0.08(0.35)$ & - \\
\hline \multirow[t]{2}{*}{ Cardiovascular } & Yes & $1313(14.9 \%)$ & $0.53(1.30)$ & $<0.0001$ & $0.32(0.74)$ & $<0.0001$ \\
\hline & No & $7474(85.1 \%)$ & $0.38(1.10)$ & - & $0.13(0.65)$ & - \\
\hline \multirow[t]{2}{*}{ Nephropathy } & Yes & $526(6.0 \%)$ & $0.63(1.43)$ & $<0.0001$ & $0.46(1.66)$ & $<0.0001$ \\
\hline & No & $8261(94.0 \%)$ & $0.39(1.11)$ & - & $0.13(0.54)$ & - \\
\hline \multirow[t]{3}{*}{ Charlson Score } & 1 & $6495(73.9 \%)$ & $0.34(1.00)$ & $<0.0001$ & $0.10(0.50)$ & $<0.0001$ \\
\hline & 2 & $1497(17.0 \%)$ & $0.53(1.46)$ & $<0.0001$ & $0.20(0.61)$ & $<0.0001$ \\
\hline & $3+$ & $795(9.1 \%)$ & $0.68(1.37)$ & - & $0.47(1.44)$ & - \\
\hline \multirow{2}{*}{$\begin{array}{l}\text { ED visits within } 6 \text { months prior to last } \\
\text { scheduled primary care appointment }\end{array}$} & Yes & $2584(29.4 \%)$ & $0.86(1.75)$ & $<0.0001$ & -+ & - \\
\hline & No & $6203(70.6 \%)$ & $0.21(0.65)$ & - & -+ & - \\
\hline \multirow{2}{*}{$\begin{array}{l}\text { Hospital admissions within } 6 \text { months prior } \\
\text { to last scheduled primary care appointment }\end{array}$} & Yes & $1081(12.3 \%)$ & -+ & - & $0.58(1.52)$ & $<0.0001$ \\
\hline & No & $7706(87.7 \%)$ & -+ & - & $0.09(0.39)$ & - \\
\hline \multirow{2}{*}{$\begin{array}{l}\text { No-show at last scheduled primary care } \\
\text { appointment }\end{array}$} & Yes & $1421(16.2 \%)$ & $0.56(1.48)$ & $<0.0001$ & $0.22(0.83)$ & $<0.0001$ \\
\hline & No & $7366(83.8 \%)$ & $0.38(1.05)$ & - & $0.14(0.63)$ & - \\
\hline
\end{tabular}

*P values are from Poisson regression. + Bivariate associations for variables that were not to be included in the multivariable analyses were not computed.

$(p<0.0001)$. Figure 1 shows that no-show status is associated with time to utilization of acute care services.

Patient characteristics that were significantly associated with the greater risk for subsequent acute care utilization (Table 1) included: female gender; aged 45 or younger; black race; non-commercial insurance; cardiovascular comorbidity; nephropathy co-morbidity; higher Charlson score; having an ED visit or hospital admission within six months prior to the last scheduled primary care appointment, and no-show at the last scheduled primary care appointment. Table 2 reveals that patient characteristics associated with no-show to the last appointment include younger age, non-white race, Medicaid insurance or selfpay, and acute care utilization in the prior six months.

Results from the Andersen Gill multiplicative hazard model revealed that no-show status was not associated with subsequent ED use after adjustment for covariates related to no-show status and ED utilization. Results from the Andersen Gill model revealed that the interaction between prior hospital admission and no-show on 

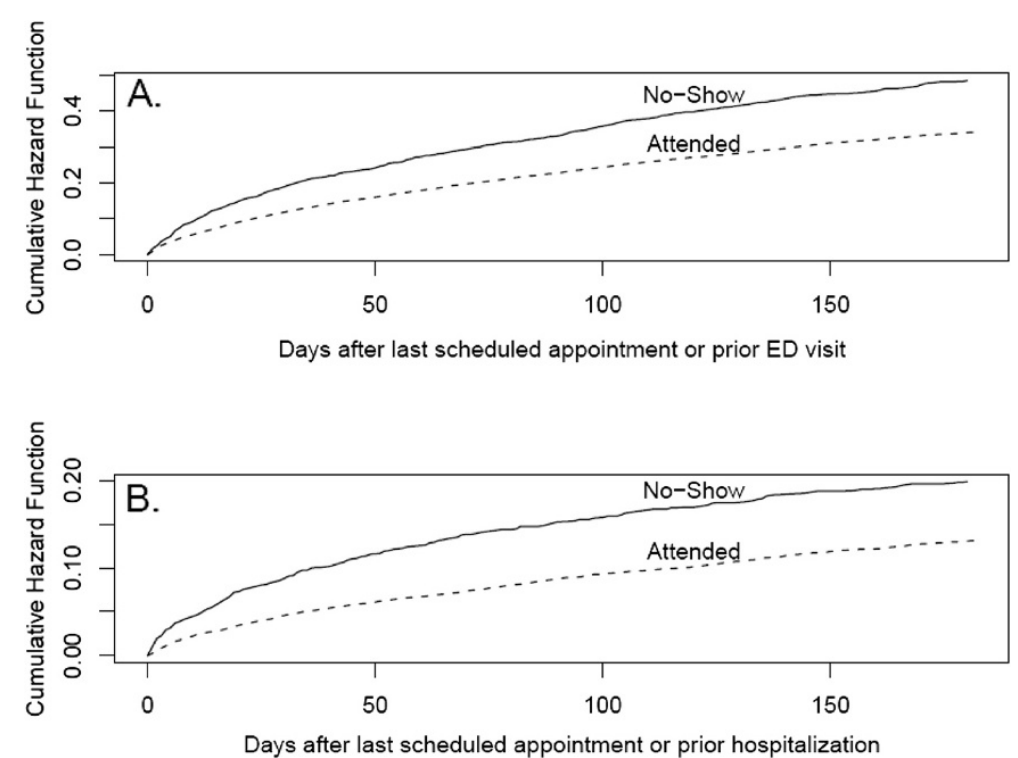

Figure 1 ED visits and Hospital admissions for diabetic patients within 6 months following the last scheduled primary care appointment.

subsequent hospital admissions was significant $(p=0.0017)$. Table 3 shows that compared to patients without a prior hospital admission and attended their appointment, those who had a prior admission and no-showed had the highest risk for subsequent hospitalization $(\mathrm{HR}=6.13$; $\mathrm{CI}=4.60-$ 8.18), followed by those with a prior hospitalization, but attended their last appointment $(\mathrm{HR}=3.84, \mathrm{CI}=3.01-4.90)$.

Among the subgroup of diabetic patients who had a prior hospital admission, those who no-showed were at $60 \%$ greater risk for subsequent hospital admission $(\mathrm{HR}=1.60$, $\mathrm{CI}=1.17-2.18)$ than those who attended their appointment. No-shows who did not have a prior admission were not at greater risk than patients without a prior hospital admission and attended their appointment $(\mathrm{HR}=0.83, \mathrm{CI}=0.63-$ 1.09). No-shows were significantly more likely to have hospital admission for diabetes diagnoses described in prior publications as potentially preventable compared to those that attended their appointment (Table 4: $13.64 \%$ versus $4.37 \%$ respectively; Chi-square $=20.47 ; \mathrm{dF}=1 ; p<=0.001$ ).

\section{Discussion}

This study provides evidence that among diabetic patients with a recent history of a hospital admission, those that no-show to their PCP appointment are at significantly greater risk for subsequent ED visits and hospital admissions than those that attended their PCP appointment. This finding confirms and extends prior research that describes the potential health consequences of patients not showing to their primary care appointment. Prior studies reported that those patients that missed their primary care appointments had poorer glycemic control $[8,11,13-16,23]$. However, prior studies have not reported that patients with diabetes who miss their medical appointments are at increased risk for subsequent hospital admissions. No-shows can disrupt continuity of care which is vital for maintenance and improvement of diabetics' health status $>[24]$. Results from this study provide evidence of the need for proactive interventions that significantly reduce no-show rates.

Acute care utilization may reflect a substitution of acute care services for primary care services for some patients [25]. A recent study revealed patients that noshowed to their primary care appointments were significantly more likely to receive their diabetes care using same-day appointments [23]. This suggests that patients that no-show may be more reactive than proactive in their approach to managing their diabetes [23]. A reactive approach is particularly problematic for patients with a recent history of hospitalization as it does not allow the opportunity for continuous treatment and monitoring of the condition that precipitated the hospital admission. This study provides indirect evidence that interruptions in primary care can contribute to poor management of diabetes because, compared to patients who attended their appointment, patients that noshowed were more likely to be admitted for diabetes diagnoses described in prior publications as potentially preventable.

Clinic-based interventions to reduce no-shows include telephone reminders which only modestly decrease no-show rate [26-28] and open access scheduling [29]. Although open access scheduling significantly reduces no-show rates, it does not adequately support chronic 
Table 2 Bivariate analysis on no-show status and other covariates

\begin{tabular}{|c|c|c|c|c|}
\hline $\mathrm{N}=8787$ & & $\mathrm{~N}(\%)$ & $\begin{array}{l}\text { No-show to last } \\
\text { scheduled appointment } \\
\mathrm{N}(\%)\end{array}$ & $P$ value* \\
\hline \multirow[t]{2}{*}{ Gender } & Female & $5268(59.9 \%)$ & $827(15.7 \%)$ & 0.14 \\
\hline & Male & $3519(40.1 \%)$ & $594(16.9 \%)$ & \\
\hline \multirow[t]{4}{*}{ Age } & $18-30$ & $314(3.6 \%)$ & $87(27.7 \%)$ & $<0.0001$ \\
\hline & $31-45$ & 1676(19.1\%) & $359(21.4 \%)$ & \\
\hline & $46-70$ & $5695(64.8 \%)$ & $837(14.7 \%)$ & \\
\hline & $\geq 71$ & $1102(12.5 \%)$ & $138(12.5 \%)$ & \\
\hline \multirow[t]{4}{*}{ Race } & Black & $3655(41.6 \%)$ & $647(17.7 \%)$ & $<0.0001$ \\
\hline & Other & $782(8.9 \%)$ & $172(22.0 \%)$ & \\
\hline & Unknown & $383(4.4 \%)$ & $67(17.5 \%)$ & \\
\hline & White & $3967(45.2 \%)$ & $535(13.5 \%)$ & \\
\hline \multirow[t]{7}{*}{ Insurance } & Medicaid & $779(8.9 \%)$ & $169(21.7 \%)$ & $<0.0001$ \\
\hline & Medicare & $2746(31.3 \%)$ & $365(13.3 \%)$ & \\
\hline & Self-pay & $471(5.4 \%)$ & 135(28.7\%) & \\
\hline & County & $2792(31.8 \%)$ & $498(17.8 \%)$ & \\
\hline & Tax-funded & & & \\
\hline & Program & & & \\
\hline & Commercial Insurance & 1999(22.8\%) & $254(12.7 \%)$ & \\
\hline \multirow[t]{2}{*}{ Cardiovascular } & Yes & $1313(14.9 \%)$ & $200(15.2 \%)$ & 0.32 \\
\hline & No & $7474(85.1 \%)$ & $1221(16.3 \%)$ & \\
\hline \multirow[t]{2}{*}{ Nephropathy } & Yes & $526(6.0 \%)$ & $83(15.8 \%)$ & 0.80 \\
\hline & No & $8261(94.0 \%)$ & $1338(16.2 \%)$ & \\
\hline \multirow[t]{3}{*}{ Charlson Score } & 1 & $6495(73.9 \%)$ & 1064(16.4\%) & 0.38 \\
\hline & 2 & 1497(17.0\%) & $242(16.2 \%)$ & \\
\hline & $3+$ & 795(9.1\%) & $115(14.5 \%)$ & \\
\hline \multirow{2}{*}{$\begin{array}{l}\text { ED visits within } 6 \text { months prior to last } \\
\text { scheduled primary care appointment }\end{array}$} & Yes & $2584(29.4 \%)$ & $553(21.4 \%)$ & $<0.0001$ \\
\hline & No & $6203(70.6 \%)$ & $868(14.0 \%)$ & \\
\hline \multirow{2}{*}{$\begin{array}{l}\text { Hospital admissions within } 6 \text { months prior to } \\
\text { last scheduled primary care appointment }\end{array}$} & Yes & $1081(12.3 \%)$ & $288(26.6 \%)$ & $<0.0001$ \\
\hline & No & $7706(87.7 \%)$ & $1133(14.7 \%)$ & \\
\hline
\end{tabular}

* $P$ values are from chi-square test.

care because the patient has to initiate the next appointment; that is, the patient has to remember to call for an appointment at the appropriate time as specified in clinical practice guidelines. Future clinic-based interventions to reduce no-show rates should consider additional modifiable clinic procedures that influence no-show rate. For example, our prior work demonstrated that patients who schedule their visit more than two weeks in advance are twice as likely to no-show to their next scheduled appointment [30]. An automated system that reminds patients to make appointments within weeks of their next needed appointment may be effective in reducing noshow rate.
Future development of clinic interventions to reduce no-show rate should consider costs of no-shows compared to costs associated with developing a multifactorial approach that includes proactive planning, scheduling, reminding and rescheduling when patients miss an appointment. Costs of no-show extend beyond lost revenue for the missed appointments [30]. This study provides evidence that costs of no-show should also include downstream costs associated with the cost of acute care that occurs after no-shows. An average charge for a hospital stay for a diabetic is nearly $\$ 11,000$ [3]. The 1421 no-shows in this study experienced an excess of 95 hospital admissions compared to subjects that 
Table 3 Hospital admissions within 6 months after last scheduled primary care appointment

\begin{tabular}{|c|c|c|c|c|c|}
\hline Parameter & & $\begin{array}{l}\text { Chi- } \\
\text { Square }\end{array}$ & $\begin{array}{l}\mathrm{Pr}> \\
\text { ChiSq }\end{array}$ & $\begin{array}{l}\text { Hazard } \\
\text { Ratio }\end{array}$ & $\begin{array}{l}95 \% \text { Hazard } \\
\text { Ratio } \\
\text { Confidence } \\
\text { Limits } \\
\end{array}$ \\
\hline Gender & Male vs. Female & 0.12 & 0.72 & 0.97 & $0.82-1.15$ \\
\hline \multirow[t]{3}{*}{ Age } & $31-45$ vs. $18-30$ & 0.29 & 0.59 & 0.89 & $0.59-1.35$ \\
\hline & $46-70$ vs. $18-30$ & 0.02 & 0.88 & 0.97 & $0.64-1.48$ \\
\hline & $\geq 71$ vs. $18-30$ & 0.007 & 0.93 & 0.98 & $0.62-1.55$ \\
\hline \multirow[t]{3}{*}{ Race } & Black vs. White & 0.39 & 0.53 & 1.05 & $0.90-1.24$ \\
\hline & Other vs. White & 0.27 & 0.61 & 1.18 & $0.63-2.23$ \\
\hline & Unknown vs. White & 3.85 & 0.05 & 0.57 & $0.33-1.00$ \\
\hline \multirow[t]{4}{*}{ Insurance } & Medicaid vs. Commercial & 21.70 & $<0.0001$ & 2.21 & $1.58-3.09$ \\
\hline & Medicare vs. Commercial & 15.19 & $<0.0001$ & 1.67 & $1.29-2.16$ \\
\hline & Self-Pay vs. Commercial & 1.85 & 0.17 & 1.31 & $0.89-1.91$ \\
\hline & County Tax-funded Program vs. Commercial & 11.37 & 0.0007 & 1.55 & $1.20-2.00$ \\
\hline Cardiovascular & Yes vs. No & 6.15 & 0.01 & 1.32 & $1.06-1.65$ \\
\hline Nephropathy & Yes vs. No & 5.29 & 0.02 & 1.40 & $1.05-1.86$ \\
\hline \multirow[t]{2}{*}{ Charlson Score } & 2 vs. 1 & 3.21 & 0.07 & 1.22 & $0.98-1.52$ \\
\hline & $\geq 3$ vs. 1 & 29.22 & $<0.0001$ & 2.05 & $1.58-2.66$ \\
\hline \multirow{6}{*}{$\begin{array}{l}\text { Status at last scheduled primary care } \\
\text { appointment and prior hospital } \\
\text { admissions within } 6 \text { months }\end{array}$} & Arrived and no prior & - & - & - & - \\
\hline & hospital admission & & & & \\
\hline & Arrived and prior & 117.01 & $<0.0001$ & 3.84 & $3.01-4.90$ \\
\hline & hospital admission & & & & \\
\hline & No-showed and no prior hospital admission & 1.84 & 0.17 & 0.83 & $0.63-1.09$ \\
\hline & No-showed and prior hospital admission & 152.09 & $<0.0001$ & 6.13 & $4.60-8.18$ \\
\hline
\end{tabular}

attended their last medical appointment. This estimate was calculated by multiplying the difference in admission rates between the attended/no-show groups to the total number of no-shows. Other potential costly consequences include potential duplication of services such as laboratory and radiology tests. Clearly, these costs provide impetus for the development of a multi-component intervention that can be implemented in the clinic setting.

The results of the study must be considered in the context of its limitations. The subjects from this study were patients enrolled in a Midwestern, urban, universityassociated primary care medical system. The demographic characteristics of this sample are similar to those of a national sample of patients with diabetes who attended academic medical centers and thus, generalizability of results may be limited to similar primary care settings [31]. The unavailability of data about the purpose of the visit appears to be a universal problem across no-show studies. No-showing to one visit is not an indicator of long-term appointment keeping behavior; however, it does provide evidence that a snapshot of no-show behavior is predictive of future acute care utilization. Furthermore, it is not possible to describe the association between no-show and medication compliance or glycemic control because not all patients' pharmacy and lab information were integrated into the medical records database. Thus, we cannot assess whether the association between no-show behavior and subsequent acute care utilization could be explained by poor glycemic control.

Table 4 Hospital admissions within 6 months following the last scheduled primary care appointment and whether the primary diagnosis was for diabetes diagnoses described in prior publications as potentially preventable

\begin{tabular}{llll}
\hline & Diabetes diagnosis (No) & Diabetes diagnosis (Yes) & Total \\
\hline Attended & $656(95.6 \%)$ & $30(4.4 \%)$ & $686(79.6 \%)$ \\
No-show & $152(86.4 \%)$ & $24(13.6 \%)$ & $176(20.4 \%)$ \\
Total & $808(93.8 \%)$ & $54(6.3 \%)$ & $862(100 \%)$ \\
\hline
\end{tabular}

${ }^{*} p<0.0001$ from chi-square test. 
This study does not capture ED visits and hospital admissions that did not occur at one of the hospitals or emergency departments associated with the three hospital systems included in the RMRS. Thus, out-of-town admissions were not included and this may have resulted in underestimation of hospital and emergency department utilization rates. This descriptive study from a clinical setting is not designed to make statements about causation. Specifically, we cannot address whether low health literacy could have explained the association between no-show status and subsequent acute care utilization. Furthermore, we were not able to describe whether there was a recursive association between noshow status and hospital admissions. By statistically adjusting for hospital admissions in the prior six months, we may have underestimated the association between no-show behavior and subsequent hospital admissions. Nonetheless, the findings provide strong evidence that among diabetics with a recent hospital admission, those who no-show are at increased risk for a future hospital admission.

\section{Conclusions}

The problem of no-shows has long been considered an outpatient clinic operations problem that disrupts providers' care plans for their chronic care patients. This study reveals that outcomes of patients who no-show extend beyond the outpatient clinic setting because patients that no-show have significantly higher rates of subsequent acute care utilization. The results provide evidence of the importance of proactive re-scheduling of patients who noshow because of their vulnerability for future hospital admissions.

\section{Competing interests}

The authors declare that they have no competing interests.

\section{Authors' contributions}

$L N, L S, M L, A T$ and ZT carried out the study, participated in data analysis and interpretation, drafted and revised the manuscript. ZT and LZ were responsible for the statistical analyses. LZ, KC and DW were involved with drafting and revising the manuscript. All authors read and approved the final manuscript.

\section{Acknowledgments}

Grant support was provided by the National Science Foundation (Award Number 0729463) and Regenstrief Center for Healthcare Engineering. Roles of these organizations included, but were not limited, funding support of personnel, travel, and other research expenses.

\footnotetext{
Author details

${ }^{1}$ School of Nursing, College of Health and Human Sciences, Purdue University, 502 N. University Street, West Lafayette, IN 47907-2069, USA. ${ }^{2}$ Weldon School of Biomedical Engineering, Purdue University, 206 S. Martin Jischke Drive, West Lafayette, IN 47907-2032, USA. ${ }^{3}$ Department of Mechanical and Industrial Engineering, Northeastern University, 360 Huntington Avenue, Boston, MA 02115, USA. ${ }^{4}$ Regenstrief Center for Healthcare Engineering, Purdue University, 203 Martin Jischke Drive, West Lafayette, IN 47907, USA. ${ }^{5}$ Department of Statistics, Purdue University, 150 N. University Street, West Lafayette, IN 47907, USA. ${ }^{6}$ Department of Family Medicine, Indiana University School of Medicine, 1110 W Michigan Street,
}

Long Hall, Suite 200, Indianapolis, IN 46202, USA. ${ }^{7}$ School of Nursing, College of Health and Human Sciences, Center for Aging and the Life Course, Purdue University, 502 N. University Street, West Lafayette, IN 47907-2069, USA.

Received: 6 March 2012 Accepted: 6 August 2012

Published: 6 September 2012

\section{References}

1. Kochanek KD, Xu JQ, Murphy SL, Minino AM, Kung HC: Deaths: Preliminary data for 2009, National Vital Statistics Reports; vol 59 no 4. Hyattsville: National Center for Health Statistics; 2011.

2. Dall TM, Zhang Y, Chen YJ, Quick WW, Yang WG, Fogli J: The economic burden of diabetes. Health Affairs 2010, 29(2):297-303.

3. Owens PL, Mutter R: Emergency Department Visits Abuse for Adults in Community Hospitals, 2008, HCUP Statistical Brief \#100. Rockville: Agency for Healthcare Research and Quality; 2010. Available from: [http://www.hcup-us. ahrq.gov/reports/statbriefs/sb100.pdf]

4. Dall TM, Mann SE, Zhang Y, Quick WW, Seifert RF, Martin J, et al: Distinguishing the economic costs associated with Type 1 and Type 2 diabetes. Popul Health Manag 2009, 12(2):103-110.

5. Fraze TK, Jiang HJ, Burgess J: Hospital Stays for Patients with Diabetes, 2008, HCUP Statistical Brief \#93. Rockville: Agency for Healthcare Research and Quality; 2010. Available from: [http://www.hcup-us.ahrq.gov/reports/ statbriefs/sb93.pdf]

6. American Diabetes Association: Standards of medical care in diabetes - 2010. Diabetes Care 2010, 33(2):S11-S61.

7. Schappert SM, Rechtsteiner EA: Ambulatory medical care utilization estimates for 2007. National Center for Health Statistics. Vital Health Stat 2011, 13(169).

8. Schectman JM, Schorling JB, Voss JD: Appointment adherence and disparities in outcomes among patients with diabetes. $J$ Gen Intern Med 2008, 23(10):1685-1687.

9. Ciechanowshi P, Russo J, Katon W, Simon G, Lundman E, Von Korff M, et al: Where is the patient? The association of psychosocial factors and missed primary care appointments in patients with diabetes. Gen Hosp Psychiatry 2006, 28(1):9-17.

10. Culica D, Walton JW, Prezio EA: CODE: Community Diabetes Education for uninsured Mexican Americans. Proc (BaylUniv Med Cent) 2007, 20(2):111-117.

11. Karter AJ, Parker MM, Moffet HH, Ahmed AT, Ferrara A, Liu JY, et al: Missed appointments and poor glycemic control: an opportunity to identify high-risk diabetic patients. Med Care 2004, 42(2):110-115.

12. Hardy KJ, O'Brien SV, Furlong NJ: Information given to patients before appointments and its effect on non-attendance rate. BMJ 2001, 323 (7324):1298-1300.

13. Griffin SJ: Lost to follow-up: the problem of defaulters from diabetes clinics. Diabet Med 1998, 15(Suppl 3):S14-S24.

14. Samuels TA, Bolen S, Yeh HC, Abuid M, Marinopoulos SS, Weiner JP, et al: Missed opportunities in diabetes management: a longitudinal assessment of factors associate with sub-optimal quality. J Gen Intern Med 2008, 23(11):1770-1777.

15. Rhee MK, Wrenn S, Ziemer DC, Culler SD, Cook CB, El-Kebbi IM, et al: Patient adherence improves glycemic control. Diabetes Educ 2005, 31 (2):240-250.

16. Davidson MB, Karlan VJ, Hair TL: Effect of a pharmacist-managed diabetes care program in a free medical clinic. Am J Med Qual 2000, 15(4):137-142.

17. Bindman AB, Grumbach $K$, Osmond D, Komaromy M, Vranizan $K$, Lurie $N$, et al: Preventable hospital admissions and access to health care. JAMA 1995, 274(4):305-311.

18. Niefeld MR, Braunstein JB, Wu AW, Sauder CD, Weller WE, Anderson GF: Preventable hospitalization among elderly Medicare beneficiaries with type 2 diabetes. Diabetes Care 2003, 26(5):1344-1349.

19. Oster $A$, Bindman $A B$ : Emergency department visits for ambulatory care sensitive conditions: insights into preventable hospitalizations. Medical Care 2003, 41(2):198-207.

20. Young BA, Lin E, Van Korff M, Simon G, Ciechanowski P, Ludman EJ, et al: Diabetes complications severity index and risk of mortality, hospitalization and healthcare utilization. Am J Manag Care 2008, 14(1):15-24.

21. Charlson ME, Pompei P, Ales KL, Mackenzie CR: A new method of classifying prognostic comorbidity in longitudinal studies: development and validation. J Chronic Dis 1987, 40(5):373-383. 
22. Andersen PK, Gill RD: Cox's regression model for counting processes: a large sample study. Annals of Statistics 1982, 10(4):1100-1120.

23. Parker MM, Moffet HH, Schillinger D, Adler N, Fernandez A, Ciechanowski P, et al: Ethnic differences in appointment-keeping and implications for the patient-centered medical home - finds from the Diabetes Study of Northern California (DISTANCE). Health Serv Res 2011, 2012, 47(2):572-593. doi:10.1111/j.1475-6773.2011.01337.x. Epub 2011 Oct 27.

24. Dearinger AT, Wilson JF, Griffith CH, Scutchfield FD: The effect of physician continuity on diabetic outcomes in a resident continuity clinic. J Gen Intern Med 2008, 23(7):937-941.

25. Billings J, Parikh N, Mijanovich T: Emergency department use in New York City: a substitute for primary care? Issue Brief (Commonw Fund) 2000, 433:1-5.

26. Koshy E, Car J, Majeed A: Effectiveness of mobile-phone short message service (SMS) reminders for ophthalmology outpatient appointments: observational study. BMC Ophthalmol 2008, 8:9.

27. Reti S: Improving outpatient department efficiency: a randomized controlled trial comparing hospital and general-practice telephone reminders. NZ Med J 2003, 116(1175):U458.

28. Hashim MJ, Franks P, Fiscella K: Effectiveness of telephone reminds in improving rate of appointments kept at an outpatient clinic: a randomized controlled trial. J Am Board Fam Pract 2001, 14(3):193-196.

29. Bundy DG, Randolf GD, Murray M, Andersen J, Margolis PA: Open access in primary care: results of a North Carolina pilot project. Pediatrics 2005, 116 (1):82-87.

30. Daggy J, Lawley M, Willis $D$, Thayer $D$, Suelzer $D$, DeLaurentis $P$, et al: Using no-show modeling to improve clinic performance. Health Informatics $J$ 2010, 16(4):246-259.

31. Grant RW, Buse JB, Meigs JB: Quality of diabetes care in U.S. academic medical centers: low rates of medical regimen change. Diabetes Care 2005, 28(2):337-342

doi:10.1186/1472-6963-12-304

Cite this article as: Nuti et al:: No-shows to primary care appointments: subsequent acute care utilization among diabetic patients. BMC Health Services Research 2012 12:304.

\section{Submit your next manuscript to BioMed Central and take full advantage of:}

- Convenient online submission

- Thorough peer review

- No space constraints or color figure charges

- Immediate publication on acceptance

- Inclusion in PubMed, CAS, Scopus and Google Scholar

- Research which is freely available for redistribution 